\title{
Considerações sobre a gênese do vale suspenso do alto Rio Preto na borda da Bacia de Resende
}

\section{Considerations about the genesis of the upper Preto River hanging valley on the border of the Resende Basin}

\author{
Éric Andrade Rezende* $₫(\mathbb{D}$, André Augusto Rodrigues Salgado $\square$ (I) \\ Instituto de Geociências, Universidade Federal de Minas Gerais, Belo Horizonte, \\ Minas Gerais, Brasil \\ E-mail: aarsalgadoufmg@gmail.com \\ *E-mail para correspondência: ericrezende@ufmg.br
}

Recebido (Received): 18/01/2020

Aceito (Accepted): 13/05/2020

\begin{abstract}
Resumo: O presente trabalho tem como objetivo investigar a gênese do vale suspenso do alto rio Preto, levando em conta seu posicionamento na borda de um rifte continental e sua proximidade com o divisor hidrográfico entre as bacias dos rios Grande e Paraíba do Sul. O alto curso do rio Preto localiza-se na Serra da Mantiqueira e estabelece a divisa entre os estados de Minas Gerais e Rio de Janeiro. A investigação teve foco na identificação de possíveis anomalias de drenagem ou controles litoestruturais e tectônicos que pudessem estar associados à formação do vale suspenso. Para isso, foi empregada a análise de modelos digitais de elevação em conjunto com perfis topográficos, mapas geológicos e observações de campo. Evidências geomorfológicas indicam que a depressão intramontana na qual se aloja o alto vale do rio Preto teve sua gênese associada primordialmente a causas erosivas e não a um escalonamento de origem tectônica que teria afetado a Serra da Mantiqueira. $\mathrm{O}$ vale suspenso pode ser interpretado como um produto da retração erosiva da borda de falha da Bacia de Resende, que localmente teria culminado em uma captura fluvial. Para a ocorrência do fenômeno, foi fundamental o paralelismo existente entre o rio Preto e a escarpa da Serra da Mantiqueira, assim como a presença de uma zona de falhas aproximadamente perpendicular à escarpa. A gênese do vale suspenso por meio de uma captura fluvial reafirma o relevante papel dos rearranjos de drenagem na evolução de flancos de rifte.
\end{abstract}

Palavras-chave: Captura fluvial; Escarpamento; Rifte do Paraíba do Sul; Serra da Mantiqueira.

Abstract: This study aims to investigate the genesis of the hanging valley of the upper Preto river, taking into account its position at the border of a continental rift and its proximity to the drainage divide between the basins of the Grande and Paraíba do Sul rivers. The upper course of Preto river is located in the Mantiqueira Range and establishes the boundary between the states of Minas Gerais and Rio de Janeiro. The investigation focused on the identification of possible drainage anomalies or lithostructural and tectonic controls that could be associated with the formation of the hanging valley. A combined analysis of digital elevation models, geological maps, topographic profiles and field observations was performed. Geomorphological evidence indicates that the intramontane depression in which the upper valley of the Preto river is located had its genesis primarily associated with erosive causes and not with tectonic movements that would form a fault staircase on the Mantiqueira Range. The hanging valley can be interpreted as a product of the erosive retraction of the fault border of the Resende Basin, which locally would have culminated in a river capture. The parallelism between the Preto river and the Mantiqueira escarpment was essential for the occurrence of the phenomenon, as well as the presence of a fault zone approximately perpendicular to the escarpment. The genesis of the hanging valley through a rivercapture reaffirms the relevant role of drainage rearrangements in the evolution of rift flanks.

Keywords: River capture; Escarpment; Paraíba do Sul Rift; Mantiqueira Range. 


\section{Introdução}

Vales suspensos são usualmente definidos como tributários com rupturas de declive abruptas e escarpadas, localizadas próximo à sua confluência com um canal coletor de maior poder erosivo (CROOSBY et al., 2007; GOODE e BURBANK, 2009). Essa configuração, onde o fundo do vale tributário é consideravelmente mais elevado que o leito do vale principal, é caraterística de ambientes glaciais montanhosos, onde uma geleira principal possui poder erosivo superior ao das geleiras tributárias. Além das áreas glaciais, os vales suspensos podem ocorrer eventualmente em outros ambientes, como em áreas cársticas, junto a escarpas de falhas jovens ou em falésias (EMBLETON-HAMANN, 2004).

Rearranjos de drenagem constituem outra possibilidade para a gênese de vales suspensos. As capturas fluviais, que ocorrem quando um canal é interceptado por outro a ele adjacente e com maior poder erosivo (SUMMERFIELD, 1991; BISHOP, 1995), são a forma de rearranjo preferencial para o desenvolvimento de segmentos fluviais altimetricamente realçados. De acordo com Babault e Van Den Driessche (2013), a ocorrência de vales suspensos associados a colos (wind-gaps) em divisores hidrográficos pode ser indicativa de capturas de cursos fluviais planálticos por canais perpendiculares que drenam as bordas do planalto e possuem nível de base local menos elevado.

Em ambientes tropicais intraplaca os vales suspensos constituem formas de relevo de ocorrência relativamente rara. No sudeste brasileiro, a presença de algumas dessas feições em bordas de planaltos que coincidem aproximadamente com divisores hidrográficos de expressão regional levou Marent e Valadão (2015) a interpretá-las como adaptações da rede hidrográfica ao processo de recuo das escarpas. No mesmo contexto, Marent e Valadão (2019) também afirmam que os vales suspensos são os registros mais marcantes de capturas fluviais resultantes da associação de processos de incisão fluvial e retração lateral das vertentes.

Contudo, ainda restam incertezas sobre a gênese de vales suspensos de diferentes dimensões, notadamente naqueles situados onde a influência da tectônica cenozoica se faz mais presente, como nos flancos do Rift Continental do Sudeste do Brasil (RICCOMINI et al., 2004). Na Serra da Mantiqueira, correspondente ao horst NNW do rifte continental, chama atenção a ocorrência de um escalonamento local de sua escarpa junto à borda da Bacia de Resende (Figura 1). No patamar intermediário ocorre uma depressão intramontana com cerca de $6 \mathrm{~km}$ de largura, na qual se aloja o alto vale do rio Preto. Esse segmento elevado do vale encontra-se cerca de $600 \mathrm{~m}$ acima do piso do graben, onde corre o rio Paraíba do Sul, e é limitado por uma notável ruptura de declive com mais de $250 \mathrm{~m}$. Embora não esteja próximo da confluência com seu coletor, como ocorre nos típicos vales suspensos, o alto rio Preto dista lateralmente apenas $20 \mathrm{~km}$ do rio Paraíba do Sul, o que torna esse segmento do vale uma feição peculiar de grande interesse para o estudo da evolução geomorfológica regional.

Nesse contexto, o presente trabalho tem como objetivo investigar a gênese do vale suspenso do alto rio Preto, levando em conta seu posicionamento na borda de um rifte continental e sua proximidade com o divisor hidrográfico entre as bacias dos rios Grande e Paraíba do Sul. Duas hipóteses foram inicialmente sugeridas. Uma primeira, de caráter morfotectônico, na qual o escalonamento da escarpa seria associado a uma escadaria de falhas na borda do graben. Na segunda hipótese, o vale suspenso teria uma gênese erosiva, associada a captura de um canal anteriormente direcionado para a bacia interiorana do rio Grande, o principal formador do rio Paraná.

Aspectos evolutivos da rede de drenagem podem ser estudados a partir da resposta das formas de relevo aos processos fluviais ou a partir dos registros sedimentares aluviais (BISHOP, 1995; CONTI, 2012). No presente trabalho foi enfatizada a abordagem morfológica, já que as condições ambientais da área não são favoráveis à preservação de sedimentos. A investigação partiu da análise do quadro geomorfológico regional e teve foco especial na identificação de possíveis anomalias de drenagem ou controles litoestruturais e tectônicos que pudessem estar associados à formação do vale suspenso. Para isso, foi empregada a análise de modelos digitais de elevação em conjunto com perfis topográficos, mapas geológicos e observações de campo. 


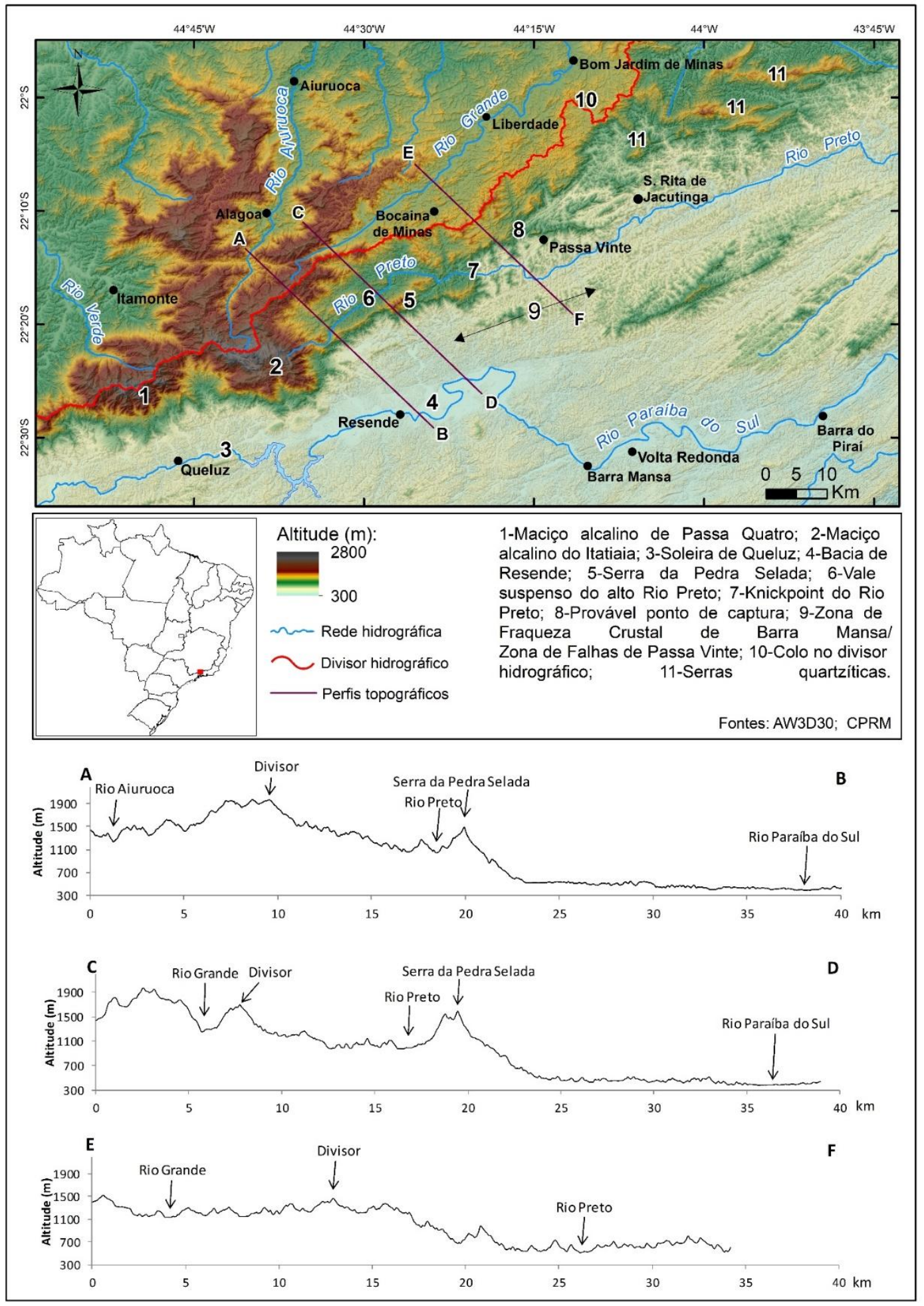

Figura 1: Localização da área de estudo, contexto geomorfológico e perfis topográficos de direção NNWSSE (A-B, C-D e E-F).

\section{Caracterização geológica-geomorfológica}

A área de estudo está inserida na Província Mantiqueira, desenvolvida durante a Orogenia Neoproterozoica Brasiliano-Pan Africana, a qual resultou na amalgamação do Paleocontinente Gondwana Ocidental (HEILBRON et al., 2004). Na proposta de compartimentação tectônica de Trouw et al. (2013), o alto vale do rio Preto situa-se no terreno Embu, próximo ao contato com o Sistema de Nappes Andrelândia, ambos inseridos na zona de interferência entre a porção meridional da Faixa Brasília e o segmento central da Faixa Ribeira. A referida zona de interferência é caracterizada pela superposição de estruturas e metamorfismo relacionados à colisão em ambas as faixas com direções de transporte tectônico e polaridades metamórficas contrastantes. Uma característica particular da Faixa Ribeira é a presença de importantes zonas de cisalhamento subverticais com movimentação destral (TROUW et al., 2013) que controlam as principais formas de relevo. As unidades pré-cambrianas da área são compostas pelo embasamento contendo 
ortognaisses de idade paleoproterozoica, metassedimentos neoproterozoicos da Megassequência Andrelândia, além de vários granitos gerados por anatexia, também neoproterozoicos (TROUW et al., 2003). A Figura 2 apresenta os principais agrupamentos de litologias e estruturas do alto vale do Rio Preto e áreas adjacentes.

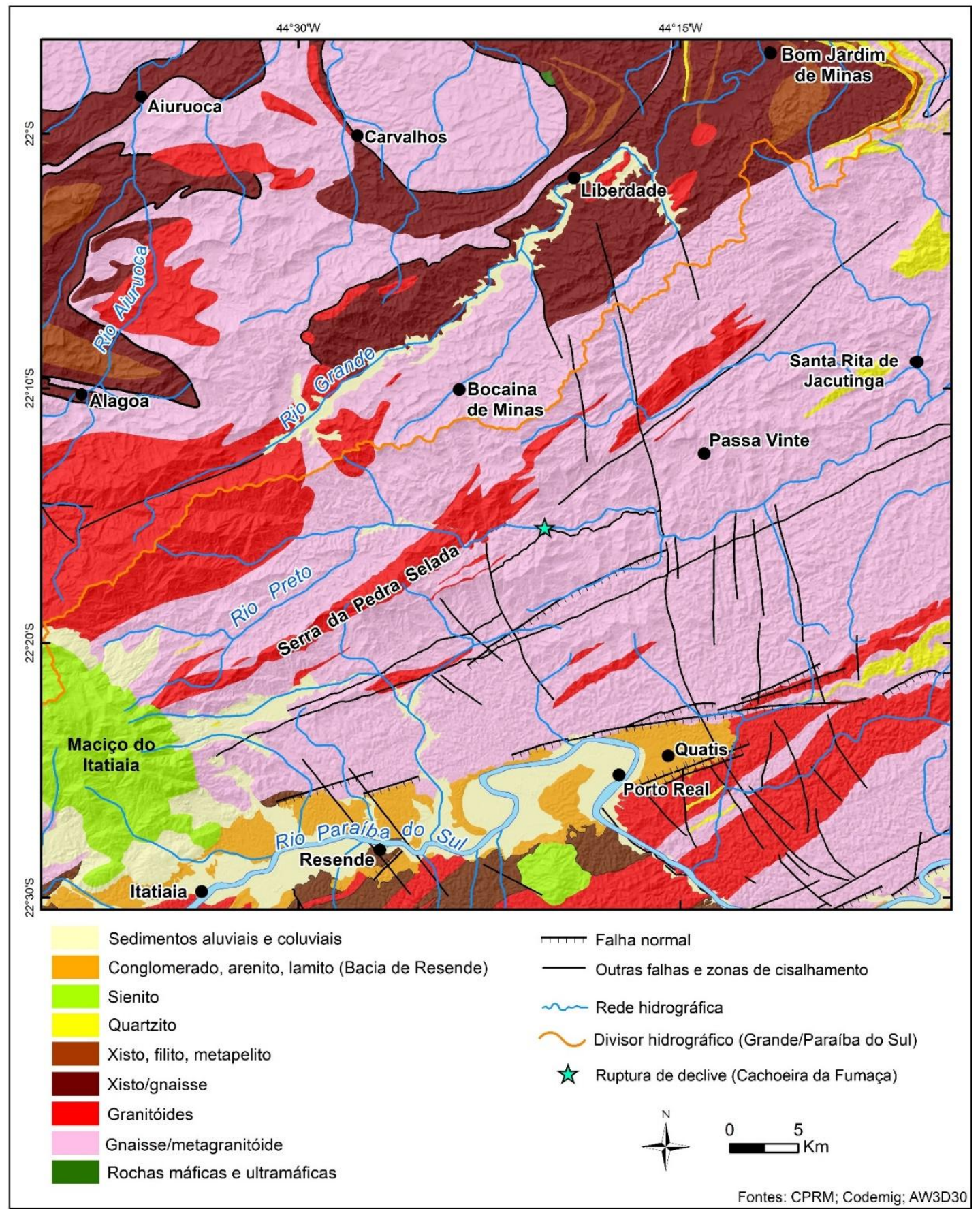

Figura 2: Mapa geológico simplificado com unidades litológicas agrupadas segundo o tipo de rocha predominante.

O relevo do sudeste brasileiro exibe a herança dos processos tectônicos cenozóicos que se seguiram à reativação Mesozoica-Cenozoica e à abertura do Oceano Atlântico (COBBOLD et al., 2001; MODENESIGAUTTIERI et al., 2002; COGNÉ et al., 2012, 2013). Durante boa parte do Cenozoico (58-20 Ma) a crosta continental fendeu-se e afundou-se em diversas áreas lineares formando corredores de grabens paralelos à costa (ZALÁN e OLIVEIRA, 2005). Essas depressões tectônicas que abrigam várias pequenas bacias sedimentares cenozoicas foram reunidas por Riccomini et al. (2004) sob a denominação de Rift Continental do Sudeste do Brasil (RCSB). A formação da depressão original do rifte e seu concomitante preenchimento sedimentar e vulcânico teriam ocorrido no Paleógeno, sob a ação de um campo de esforços distensivo de direção NNW-SSE. Tal fato causou a reativação, como falhas normais, de antigas zonas de cisalhamento proterozoicas de direção NE a ENE. Posteriormente, quatro fases tectônicas deformadoras envolveram novas 
reativações ao longo das falhas preexistentes e, em menor escala, a geração de novas estruturas (RICCOMINI et al., 2004). A Bacia de Resende é uma das bacias sedimentares alojadas nos blocos que sofreram abatimentos significativos em meio às montanhas soerguidas por rebatimento elástico (ZALÁN e OLIVEIRA, 2005). De acordo com Santos (1999) e Heilbron (2007), os registros fanerozoicos dessa porção da Serra da Mantiqueira e áreas adjacentes correspondem a: (i) diques de diabásio e intrusões alcalinas cretácicas (maciços de Itatiaia, Passa-Quatro e Morro Redondo); (ii) depósitos sedimentares e rochas vulcânicas das bacias paleógenas (Taubaté, Resende, Volta Redonda e Aiuruoca); (iii) depósitos quaternários.

O alto vale do rio Preto está situado a leste do Maciço do Itatiaia, que abriga alguns dos pontos de maior altitude do sudeste brasileiro (> $2500 \mathrm{~m}$ ) e constitui uma importante área de irradiação de drenagem (Figura 1). A declividade das encostas frequentemente ultrapassa $30 \%$ e as amplitudes entre topos de morros e fundos de vales geralmente superam 100 m. Conforme observado por Santos (1999), a drenagem da área é muito densa e apresenta pronunciada incisão, sendo caracterizada por corredeiras e cachoeiras correndo diretamente sobre a rocha. Planícies aluviais de maior expressão ocorrem apenas nos trechos de menor gradiente dos cursos de fluviais de maior ordem, como o próprio rio Preto e o rio Grande.

\section{Materiais e métodos}

Inicialmente foi realizada uma análise do quadro geomorfológico regional, com atenção especial ao arranjo altimétrico dos principais vales nas adjacências do divisor entre as bacias dos rios Grande e Paraíba do Sul. Para isso, foi empregada a análise visual de modelo digital de elevação (MDE) AW3D30 no sistema de informação geográfica ArcGis 10. Na mesma plataforma, foram elaborados três perfis topográficos perpendiculares aos principais vales e estruturas do rifte continental para uma melhor avaliação das variações altimétricas. Ao mesmo tempo, foi investigada a ocorrência de possíveis anomalias de drenagem, como cotovelos de captura, colos nos divisores (wind gaps) e rupturas de declive associadas a vales suspensos (SUMMERFIELD, 1991; BISHOP, 1995; BABAULT e VAN DEN DRIESSCHE, 2013). Devido à configuração altimétrica anômala de seu alto vale em relação ao nível de base regional, o rio Preto foi selecionado para a confecção de um perfil longitudinal, de modo a evidenciar suas principais rupturas de declive. Os dados altimétricos dos perfis gerados no ArcGis foram tratados em planilha eletrônica, onde foram então produzidos os gráficos finais.

A opção pela utilização dos dados AW3D30 se deve ao fato deles oferecerem o maior potencial para análises geomorfológicas regionais em áreas montanhosas entre os MDEs de média resolução (BOULTON e STOKES, 2018). De acordo com Tadono et al. (2016), a Agência Espacial Japonesa produziu esse modelo altimétrico através de fotogrametria orbital pelo sensor PRISM do satélite ALOS. O MDE, originalmente gerado com resolução espacial de $5 \mathrm{~m}$, foi reamostrado e disponibilizado com uma resolução espacial de 1 arco-segundo $(30 \mathrm{~m})$. A partir do MDE, foram produzidas camadas de declividade (slope) e de relevo sombreado (hillshade), que foram a ele combinadas de modo a aumentar o nível de detalhe de alguns elementos do relevo e possibilitar a adição de aspectos texturais à elevação (MAYER, 2000; TINÓS et al., 2014).

Os dados geológicos utilizados nas análises em conjunto com o MDE foram obtidos em mapas na escala de 1:100.000, correspondentes às folhas Pouso Alto (TROUW et al., 2003) e Santa Rita de Jacutinga (HEILBRON, 2007). De modo a facilitar a verificação de controles litológicos sobre o relevo, foi feito um agrupamento das unidades litológicas de acordo com o(s) tipo(s) de rocha predominante(s) (Figura 2). Para a definição dos grupos foram utilizados como base os mapas geológicos de Minas Gerais (PINTO e SILVA, 2014) e do Rio de Janeiro (HEILBRON et al., 2016) em conjunto com os mapas na escala de 1:100.000. Além disso, foi incorporada ao sistema de informação geográfica uma camada vetorial referente à rede hidrográfica oriunda das folhas topográficas do IBGE na escala de 1:50.000.

A análise integrada dos diferentes produtos cartográficos por meio do ArcGis 10 permitiu verificar o arranjo espacial da rede hidrográfica e a disposição desta em relação aos divisores de drenagem, cristas, escarpamentos, depressões, estruturas geológicas e litologias. Atenção especial foi dada às ocorrências de sedimentos cenozoicos presentes nos mapeamentos geológicos. A abordagem utilizada na investigação apoiou-se em alguns modelos de evolução de escarpamentos e da rede de drenagem a eles associada (SUMMERFIELD, 1991; MATMON et al., 2002; OLLIER, 2004).

Trabalhos de campo com foco na região dos baixos divisores e nos vales do alto curso do rio Preto e do alto rio Grande foram realizados para busca de registros sedimentares possivelmente vinculados a posições pretéritas da rede de drenagem, assim como para a conferência das principais feições indicativas de 
rearranjos de drenagem previamente interpretadas nos trabalhos cartográficos. As observações foram feitas ao longo das principais vias, como a MG-457, a LMG-814 e a RJ-151, além de estradas vicinais.

\section{Resultados e discussões}

\subsection{Caracterização do vale suspenso}

O trecho da Serra da Mantiqueira a NNW da Bacia de Resende tem como peculiaridade o fato de sua face sudeste apresentar um escalonamento composto por dois degraus paralelos de direção NE-SW (Figura 1). Essa configuração difere do que ocorre a oeste, entre o Planalto de Campos de Jordão e o Maciço do Itatiaia, onde há um único degrau abrupto que, em geral, tem topo coincidente com o divisor hidrográfico Grande/Paraíba do Sul.

Na borda da Bacia de Resende, uma primeira escarpa separa a depressão do médio Paraíba do Sul de um patamar intermediário constituído pela alta bacia do rio Preto (Figura 1). Embora a altura predominante dessa escarpa seja de aproximadamente $700 \mathrm{~m}$, em alguns pontos ela chega a superar $1000 \mathrm{~m}$, como no Pico da Pedra Selada, sustentado por granitos e situado a $1755 \mathrm{~m}$ de altitude. Esse escarpamento é resultante do recuo da borda de falha da Bacia de Resende desde o Paleógeno, quando foi formado o segmento central do Rift Continental do Sudeste do Brasil, como indicam Moreira et al. (2012).

O patamar intermediário, no qual se encontra o distrito de Visconde de Mauá/RJ (Figura 3A), é constituído por morros e colinas com altitudes predominantes entre 1000 e $1200 \mathrm{~m}$, embora algumas cristas isoladas superem $1300 \mathrm{~m}$. Esse compartimento encontra-se levemente rebaixado em relação ao reverso da escarpa inferior, pela qual é limitado a sudeste. Seu limite sudoeste corresponde ao imponente Maciço do Itatiaia, onde se localiza a nascente do Rio Preto. Toda sua área é pertencente à bacia do rio Paraíba do Sul, sendo drenada pelo alto rio Preto e seus afluentes. Portanto, esse patamar corresponde a um vale suspenso, no qual o rio Preto possui um nível de base consideravelmente acima daquele existente na depressão do médio Paraíba do Sul (Figura 1).

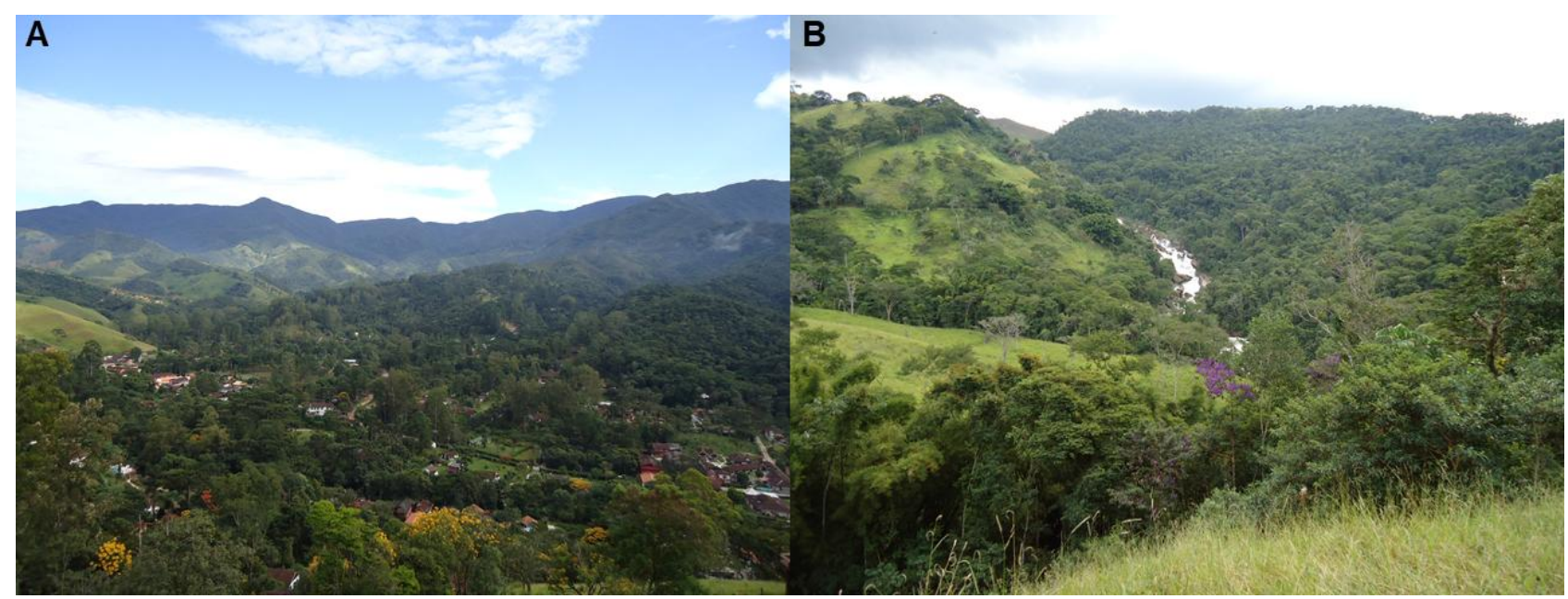

Figura 3: A) Vale do alto rio Preto, com escarpa da Serra da Mantiqueira ao fundo. Vista para NNW a partir do povoado de Maringá/RJ. B) Visão parcial da cachoeira da Fumaça, correspondente à zona de ruptura no perfil longitudinal do rio Preto que estabelece o limite do vale suspenso. A foto mostra a parte inferior da queda d'água.

A noroeste do patamar intermediário ergue-se uma segunda escarpa paralela à primeira, com altura próxima dos $1000 \mathrm{~m}$, como ilustram os perfis topográficos A-B e C-D da Figura 1. Esse escarpamento não é tão retilíneo e declivoso quanto o anterior. Sua principal caraterística é a alternância entre reentrâncias, onde alojam-se os principais cursos fluviais, e saliências, marcadas por divisores de topos alongados e angulosos (Figura 3A).

O topo da escarpa superior, localmente posicionado entre 1600 e $2250 \mathrm{~m}$ de altitude, possui morfologia convexa a aguçada e abriga o divisor hidrográfico entre as bacias dos rios Grande (Paraná) e Paraíba do Sul. Esse divisor, que no Maciço do Itatiaia ultrapassa os $2500 \mathrm{~m}$ de altitude, decai progressivamente em direção a nordeste, raramente superando $1600 \mathrm{~m}$ a leste da área de estudo. 


\subsection{Hipóteses e evidências de processos envolvidos na gênese do vale suspenso}

A hipótese de uma origem tectônica para o degrau no qual se aloja o vale suspenso vai ao encontro da morfologia tradicionalmente atribuída aos riftes, onde uma depressão central é flanqueada por duas ombreiras soerguidas, cada uma das quais associada a uma escadaria de falhas que mergulham em direção à depressão (FROSTICK, 2004). Na Serra da Mantiqueira a ocorrência de uma escadaria de falhas já era postulada em estudos pioneiros, como o de Emmanuel de Martonne (1943). Contudo, estudos posteriores demonstraram que a Bacia de Resende não está situada em um rifte simétrico, mas sim em um hemi-graben com forte controle tectônico em sua borda ativa, situada a NNW (RICCOMINI et al., 2004; RAMOS et al., 2005; ZALÁN e OLIVEIRA, 2005).

Os modernos mapeamentos geológicos apontam a existência de um alinhamento principal de falhas normais ENE que afeta a borda NNW da Bacia de Resende (RAMOS et al., 2005; HEILBRON, 2007), conforme mostra a Figura 2. Essas falhas encontram-se no contato entre os sedimentos paleogênicos e as rochas pré-cambrianas. Um segundo alinhamento de extensão reduzida ocorre junto ao sopé da Serra da Pedra Selada, ainda no piso da atual depressão (Figura 2). No patamar que abriga o vale suspenso não há falhas mapeadas (Figura 2) ou feições morfotectônicas que indiquem a presença de falhas neocenozoicas de direção ENE e com rejeito da ordem de centenas de metros, como seria esperado caso o escalonamento da escarpa fosse de origem tectônica.

Paralelamente, caso o responsável pelo escalonamento local da escarpa da Serra da Mantiqueira fosse unicamente a movimentação diferencial de blocos, essa configuração provavelmente não se restringiria aos $56 \mathrm{~km}$ iniciais do vale do rio Preto, mas ocorreria também em outros trechos da escarpa principal do rifte continental. Observa-se ainda que o escalonamento topográfico regional atribuído a causas tectônicas ocorre no sentido oposto, ou seja, para NNW a partir dos topos da Mantiqueira (SAADI, 1991; SANTOS, 1999), como indica o perfil topográfico A-B da Figura 1.

Por outro lado, são várias as evidências de uma origem erosiva do vale suspenso, possivelmente atrelada a rearranjos de drenagem. A primeira está impressa na diferença altimétrica existente entre os compartimentos de relevo que abrigam os vales aproximadamente paralelos dos rios Grande, Preto e Paraíba do Sul. Localmente, a diferença altimétrica entre o vale do alto rio Preto $(900$ a $1100 \mathrm{~m}$ ) e o vale do alto rio Grande (1100 a $1200 \mathrm{~m}$ ) é da ordem de 100/200 m, enquanto o desnível daquele primeiro em relação à depressão do médio rio Paraíba do Sul chega a $600 \mathrm{~m}$. Ou seja, o alto rio Preto está posicionado em um nível altimétrico semelhante ao do rio Grande, embora seja tributário do rio Paraíba do Sul e diste lateralmente deste apenas $20 \mathrm{~km}$ (Figura 1). Logo, em termos morfotectônicos, os rios Grande e Preto drenam o mesmo compartimento, localizado no horste do rifte continental (Serra da Mantiqueira). Já o médio rio Paraíba do Sul, constitui uma típica drenagem axial de rifte, que tem seu curso instalado no piso do graben. Sendo assim, do ponto de vista do condicionamento morfotectonico sobre a organização da rede de drenagem, é plausível supor que o rio Preto deveria drenar em direção ao rio Grande e constituir a principal nascente desse curso fluvial que é o formador mais distante e elevado do rio Paraná.

Outra evidência de que o rio Preto teria sido alvo de uma captura fluvial é a presença de uma acentuada ruptura de declive (knickpoint) que marca a transição brusca do seu alto curso, localizado no vale suspenso, para o seu médio curso, já inserido na depressão do rio Paraíba do Sul (Figura 4). Nessa ruptura, o rio Preto apresenta aspecto encachoeirado em uma imponente queda com mais de $250 \mathrm{~m}$ (Figura 3B), o que a torna uma das maiores quedas d'água do sudeste brasileiro. O limite oriental do vale suspenso encontra-se a cerca de $882 \mathrm{~m}$ de altitude e marca o início do trecho localmente conhecido como Cachoeira da Fumaça. Na base do trecho encachoeirado, a $628 \mathrm{~m}$ de altitude, o rio passa a apresentar um gradiente mais moderado (Figura 4), que já se mostra parcialmente adaptado ao nível de base da depressão tectônica. Vale ressaltar que o knickpoint em questão não apresenta controle litológico evidente, já que se localiza inteiramente sobre unidades gnáissicas (Figura 2). 


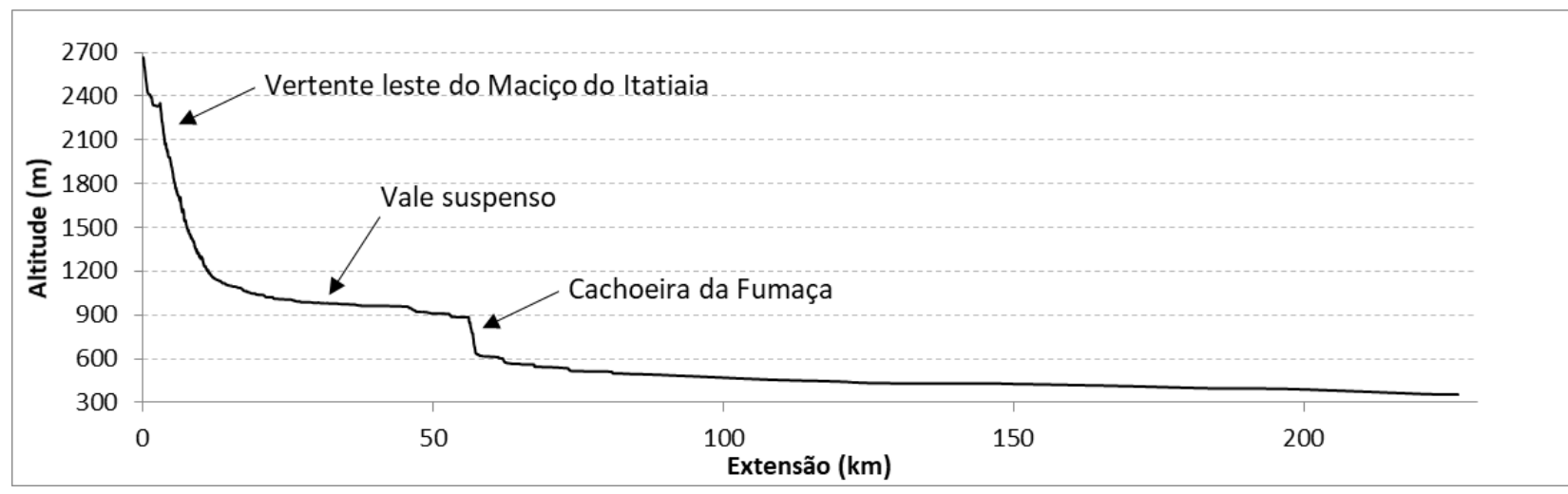

Figura 4: Perfil longitudinal do rio Preto traçado entre sua nascente e a confluência com o rio Paraibuna.

Chama atenção também o fato de o rio Grande correr, em seu alto curso, na direção NE, paralelo ao divisor regional e bastante próximo deste, sem possuir nenhum grande afluente de margem direita (Figura 1). Essa ausência de grandes afluentes pode ser atribuída ao crescente recuo da escarpa da Serra da Mantiqueira a leste da Bacia de Resende. Sobre isto, Hasui et al. (1982) observaram que caso a Mantiqueira a ENE do Maciço do Itatiaia teve sua origem em zona de falha, a erosão fez recuar muito suas escarpas para além dessas falhas, ao contrário do que ocorreu na borda da Bacia de Taubaté. A maior intensidade do recuo erosivo a leste da Bacia de Resende é evidenciada pela presença de elevações residuais quartzíticas em meio à depressão do Paraíba do Sul, a NNW de Santa Rita de Jacutinga (Figuras 1 e 2). A alta resistência dos quartzitos aos processos denudacionais impediu que essas cristas fossem arrasadas, embora o divisor hidrográfico tenha continuado sua migração em direção ao interior. Ou seja, a partir dessa área a escarpa da Serra da Mantiqueira deixa de apresentar um nítido controle tectônico e passa a se configurar como uma legítima escarpa erosiva, geneticamente associada à abertura das depressões dos rios Paraibuna e Pomba, ambos afluentes do rio Paraíba do Sul (MARENT e VALADÃO, 2015; MARENT et al., 2017; MARQUES NETO et al., 2019). Nesse contexto, o recuo do escarpamento se deu principalmente por capturas fluviais que pouco a pouco incorporaram, desnudaram e rebaixaram bacias de drenagem planálticas (CHEREM et al., 2013; SALGADO et al., 2012; PAIXÃO et al., 2019).

O recuo crescente das escarpas que limitam a bacia do rio Paraíba do Sul está diretamente relacionado à presença de dois importantes níveis de base: as soleiras de Queluz e de Sapucaia. A soleira de Queluz (ponto 3 na Figura 1), também denominada Alto Estrutural de Queluz, é uma feição estrutural positiva que separa as bacias de Taubaté e Resende (SALVADOR e RICCOMINI, 1995). A montante dessa soleira, a depressão do Paraíba do Sul apresenta altitudes sempre superiores a $500 \mathrm{~m}$ e as escarpas encontram-se pouco recuadas. A jusante, a depressão rapidamente atinge níveis inferiores a $400 \mathrm{~m}$ de altitude, e o recuo das escarpas aumenta progressivamente. Já o "Estreito de Sapucaia", localizado cerca de $200 \mathrm{~km}$ a jusante da Bacia de Resende, corresponde a um estrangulamento no vale do rio Paraíba do Sul (SARTI, 2008). A jusante desse nível de base, o recuo erosivo processado pela rede de drenagem ligada aos rios Pomba e Muriaé abriu uma vasta depressão que extrapola largamente os limites do Rifte do Paraíba do Sul definidos por Zalán \& Oliveira (2005). O controle exercido pelas soleiras também é verificado através de dados termocronológicos que inferem denudação cenozoica crescente em direção a jusante (leste) no vale do Paraíba do Sul. De acordo com Oliveira et al. (2016), o total denudado varia de cerca de $2000 \mathrm{~m}$ (30 m/Ma) no médio curso até $3000 \mathrm{~m}(45 \mathrm{~m} / \mathrm{Ma})$ no baixo curso.

$\mathrm{O}$ mecanismo de captura aparenta estar diretamente associado a falhas pertencentes à Zona de Fraqueza Crustal de Barra Mansa (ALMEIDA et al., 1999) ou Zona de Falhas de Passa Vinte (SAADI, 1991). Essa zona de fraqueza de direção geral N-S influencia fortemente a dissecação do relevo (ALMEIDA et al, 1999) e suas principais estruturas encontram-se representadas na Figura 2. Também foi fundamental para a captura fluvial o paralelismo existente entre o rio Preto e a escarpa da Serra da Mantiqueira, já que essa configuração favorece que canais desenvolvidos na face escarpada interceptem graças à erosão regressiva os rios que fluem paralelos à elevação (OLLIER, 2004). No caso da área de estudo, provavelmente, um antigo afluente do rio Paraíba do Sul aproveitou-se de uma das falhas de direção NNW-SSE para promover um intenso recuo através da escarpa, obliterando o divisor até atingir o rio Preto para assim desviar suas águas. Situação semelhante foi descrita por Modenesi-Gauttieri et al. (2002) no Planalto de Campos do Jordão (Mantiqueira Ocidental), onde as interseções de falhas NNW e NE são os locais preferenciais de capturas observadas nas cabeceiras ao longo do divisor.

A não preservação das antigas linhas de drenagem, somada às condições ambientais desfavoráveis à conservação de registros sedimentares, impede que seja reconstruída a localização da provável confluência 
entre o rio Preto ancestral e o rio Grande. No entanto, é plausível supor que esta se encontrasse próxima à cidade de Bom Jardim de Minas/MG, já que as porções menos elevadas do divisor regional estão ali situadas (ponto 10 na Figura 1). Nesse trecho, o divisor é pouco nítido na paisagem e não coincide com o topo da escarpa. Em seu ponto mais baixo, no limite entre os municípios de Bom Jardim de Minas e Santa Rita de Jacutinga, está posicionado a apenas $1230 \mathrm{~m}$ de altitude, enquanto as cristas adjacentes superam $1400 \mathrm{~m}$. Portanto, esse colo pode representar a herança topográfica de um paleovale (wind gap), possivelmente associado a um rio Preto ancestral.

$\mathrm{O}$ arrasamento erosivo das antigas linhas de drenagem e a diferença altimétrica superior a $200 \mathrm{~m}$ entre o vale do rio Preto e o colo no divisor indicam que se trata de um rearranjo de drenagem provavelmente anterior ao Quaternário. O considerável volume denudado pós-captura demandaria um tempo superior a 2,5 Ma para ser removido, caso considere-se a vigência das taxas de denudação inferiores a $30 \mathrm{~mm} / \mathrm{ka}$ mensuradas na Serra da Mantiqueira (REZENDE et al., 2013; SALGADO et al., 2016; SOUZA et al., 2019). $\mathrm{O}$ fato de o Mioceno ser reconhecidamente marcado por amplas alterações no sistema de drenagem do Paraíba do Sul (COBBOLD et al. 2001; COGNÉ et al., 2012; OLIVEIRA et al., 2016) sugere uma idade máxima miocênica para a captura fluvial em questão, o que não exclui a possibilidade que a mesma tenha ocorrido ainda durante o Plioceno.

\section{Considerações finais}

As evidências geomorfológicas apresentadas indicam que a depressão intramontana na qual se aloja o alto vale do rio Preto teve sua gênese associada primordialmente a causas erosivas e não a um escalonamento de origem tectônica que teria afetado a Serra da Mantiqueira. $O$ vale suspenso inserido na depressão intramontana pode ser interpretado como um produto da retração erosiva da borda de falha da Bacia de Resende, que localmente teria culminado em uma captura fluvial. Para a ocorrência do fenômeno foi preponderante o fato de o vale ser paralelo à escarpa, assim como a existência de uma zona de falhas perpendicular às estruturas do rifte. Essa configuração favoreceu a interceptação de um ancestral do rio Preto por um canal capturador voltado para o graben. O mais notável registro morfológico do processo de captura é uma ruptura de declive com mais de $250 \mathrm{~m}$ de desnível na extremidade do vale suspenso. Deste modo, reafirma-se o relevante papel dos rearranjos de drenagem na evolução geomorfológica de flancos de rifte, como apontado em modelos evolutivos elaborados por Summerfiel (1991) e Ollier (2004).

Merece destaque que uma antiga configuração da rede de drenagem onde o alto rio Preto pertencesse à bacia hidrográfica do rio Paraná faria com que sua nascente se tornasse a mais elevada e mais distante de tal bacia. Sendo assim, o processo de captura fluvial aqui evidenciado teria sido responsável por fazer com que o rio Preto deixasse de constituir a principal nascente do rio Paraná e passasse a ser um afluente do rio Paraíba do Sul.

\section{Referências}

ALMEIDA, J. C. H.; EIRADO, L. G.; DIOS, F. R. B.; GONTIJO, A. H. F.; HEILBRON M.; VALERIANO, C. M. A Zona de Fraqueza Crustal de Barra Mansa. In: SIMPÓSIO DE GEOLOGIA DO SUDESTE, 6. 1999, São Pedro-SP. Boletim de Resumos. São Paulo: Sociedade Brasileira de Geologia, 2000. p. 96.

BABAULT, J.; VAN DEN DRIESSCHE, J. Plateau uplift, regional warping, and subsidence. In: SHRODER, J. (Editor in Chief), OWEN, L. A. (Ed.). Treatise on Geomorphology. San Diego: Academic Press, vol. 5, 2013 p. 93-128. https://doi.org/10.1016/B978-0-12-374739-6.00087-7

BISHOP, P. Drainage rearrangement by river capture, beheading and diversion. Progress in physical geography, v. 19, n. 4, p. 449-473, 1995. https://doi.org/10.1177/030913339501900402

BOULTON, S. J.; STOKES, M. Which DEM is best for analyzing fluvial landscape development in $\begin{array}{lllllll}\text { mountainous } & \text { terrains?. Geomorphology, } & \text { v. } & 310, & \text { p. } & 168-187, & 2018 .\end{array}$ https://doi.org/10.1016/j.geomorph.2018.03.002

CHEREM, L. F. S.; VARAJÃO, C. A. C.; MAGAlhãeS JÚNiOR, A. P.; VARAJÃO, A. F. D. C.; SALGADO, A. A. R.; OLIVEIRA, L. A. F.; BERTOLINI, W. Z. O papel das capturas fluviais na morfodinâmica das bordas interplanálticas do sudeste do Brasil. Revista Brasileira de Geomorfologia, v. 14, p. 299-308, 2013. https://doi.org/10.20502/rbg.v14i4.325 
COBBOLD, P. R, MEISLING, K. E., MOUNT, V.S. Reactivation of an obliquely rifted margin, Campos and Santos basins, southeastern Brazil. AAPG Bulletin, v. 85, n. 11, p.1925-1944, 2001.

https://doi.org/10.1306/8626D0B3-173B-11D7-8645000102C1865D

COGNÉ, N.; GALLAGHER, K.; COBBOLD, P. R.; RICCOMINI, C.; GAUTHERON, C. Post-breakup tectonics in southeast Brazil from thermochronological data and combined inverse-forward thermal history modeling. Journal of Geophysical Research: Solid Earth, v. 117, n. 11, p. 1-16, 2012. https://doi.org/10.1029/2012JB009340

COGNÉ, N.; COBBOLD, P.R.; RICCOMINI, C.; GALLAGHER, K. Tectonic setting of the Taubaté Basin (Southeastern Brazil): Insights from regional seismic profiles and outcrop data. Journal of South American Earth Sciences, v. 42, p. 194-204, 2013. https://doi.org/10.1016/j.jsames.2012.09.011

CONTI, L.A. Paleodrainage Systems. In: JAVAID, M. S. (ed.) Drainage Systems. Rijeka: IntechOpen, 2012. p. 3-20.

CROSBY, B. T.; WHIPPLE, K. X.; GASPARINI, N. M.; WOBUS, C. W. Formation of fluvial hanging valleys: Theory and simulation. Journal of Geophysical Research: Earth Surface, v. 112, n. F3, 2007. https://doi.org/10.1029/2006JF000566

EMBLETON-HAMANN, C. Hanging valley. In: GOUDIE, A. S. (ed.). Encyclopedia of geomorphology. Routledge, 2004. v. 1. p. 513.

FROSTICK, L. Rift Valley and rifting. In: GOUDIE, A. S. (ed.). Encyclopedia of Geomorphology. London: Routledge, 2004. v. 2. p. 849-852.

GOODE, J. K.; BURBANK, D. W. Numerical study of degradation of fluvial hanging valleys due to climate change. Journal of Geophysical Research: Earth Surface, v. 114, n. F1, 2009. https://doi.org/10.1029/2007JF000965

HEILBRON, M.; PEDROSA-SOARES, A. C.; CAMPOS NETO, M. D. C.; SILVA, L. D.; TROUW, R. A. J.; JANASI, V. D. A. Província Mantiqueira. In: MANTESSO-NETO, V.; BARTORELLI, A.; CARNEIRO, C. D. R.; BRITO-NEVES, B. B. (org). Geologia do Continente Sul-Americano: Evolução da Obra de Fernando Flávio Marques de Almeida, São Paulo: Beca, 2004. p. 203-234.

HEILBRON, M. (Coord.). Volta Redonda- SF.23-Z-A-V, escala 1:100.000: nota explicativa integrada com Santa Rita do Jacutinga, Barra do Piraí, Angra dos Reis. In: CPRM. Geologia da folha Volta Redonda SF.23-Z-A-V. Rio de Janeiro/São Paulo: UERJ/CPRM, 2007. CD-ROM.

HEILBRON, M.; EIRADO, L. G.; ALMEIDA, J. Mapa Geológico e de Recursos Minerais do Estado do Rio de Janeiro. Escala 1:400.000. CPRM-Serviço Geológico do Brasil, Superintendência Regional de Belo Horizonte, 2016.

MARENT, B. R.; VALADÃO, R. C. Compartimentação Geomorfológica dos Planaltos Escalonados do Sudeste de Minas Gerais - Brasil. Revista Brasileira de Geomorfologia, v. 16, n. 2, 2015. https://doi.org/10.20502/rbg.v16i2.634

MARENT, B. R.; VALADÃO, R. C. Contribuição aos estudos da evolução da escarpa entre as bacias hidrográficas dos rios Doce e Paraíba do Sul, na Serra da Mantiqueira-MG-Brasil. Geousp - Espaço e Tempo (Online), v. 23, n. 2, p. 417-434, ago. 2019.https://doi.org/10.11606/issn.21790892.geousp.2019.137398

MARENT, B. R.; VAlADÃO, R. C.; MANFRÉ, L. A.; NÓBREGA, R. A. A.; HENRIQUES, R. J. Interação nível de base e dissecação de bacias hidrográficas no Sudeste de Minas Gerais - Brasil. Caminhos de Geografia, v. 19, n. 68, p. 215-232, 2018. https://doi.org/10.14393/RCG196815 
MARQUES NETO, R.; MOREIRA, J. A.; SILVA, F. P. Evolução de escarpamento em margens rifte: uma discussão sobre soerguimento e desnudação na Mantiqueira Meridional a partir de mapas paleotopográficos e parâmetros geomorfométricos. Revista Brasileira de Geomorfologia, v. 20, n. 4 p. 877-890, 2019. http://dx.doi.org/10.20502/rbg.v20i4.1577

MARTONNE, E. Problemas morfológicos do Brasil tropical atlântico - Parte 1. Revista Brasileira de Geografia, v. 5, n. 4, p. 155-178, 1943.

MATMON, A.; BIERMAN, P.; ENZEL, Y. Pattern and tempo of great escarpment erosion. Geology; v. 30, n. 12, p. 1135-1138, 2002. https://doi.org/10.1130/0091-7613(2002)030<1135:PATOGE>2.0.CO;2

MAYER, L. Application of digital elevation models to macroscale tectonic geomorphology. In: SUMMERFIELD, M. (Ed.). Geomorphology and Global Tectonics. Chichester: John Wiley \& Sons Ltd., 2000. p. 15-26.

MODENESI-GAUTTIERI, M. C.; HIRUMA, S. T.; RICCOMINI, C. Morphotectonics of a high plateau on the northwestern flank of the Continental Rift of southeastern Brazil. Geomorphology, v. 43, p. 257 - 271, 2002. https://doi.org/10.1016/S0169-555X(01)00137-4

MOREIRA, I. C.; MELLO, C. L.; FERNADES, N. F. Aplicação de modelo matemático de evolução do relevo na simulação do recuo da escarpa de porção da Serra da Mantiqueira, Resende/Itatiaia (RJ). In: SIMPÓSIO NACIONAL DE GEOMORFOLOGIA, 9., 2012, Rio de Janeiro. Anais... Rio de Janeiro: UGB, 2012. CD-ROM.

OLIVEIRA, C. H. E.; JLINEK, A. R.; CHEMALE, F.; CUPERTINO, J. A. Thermotectonic history of the southeastern Brazilian margin: Evidence from apatite fission track data of the offshore Santos Basin and continental basement. Tectonophysics, v. 685, p. 21-34, 2016. https://doi.org/10.1016/j.tecto.2016.07.012

OLLIER, C. The evolution of mountains on passive continental margins. In: OWENS, P.N.; SLAYMAKER, O. (Eds). Mountain Geomorphology. London: Edward Anold (Publishers) Ltd, 2004.

PAIXÃO, R. W.; SAlgAdO, A. A. R.; FREITAS, M. M. Morfogênese do divisor hidrográfico Paraná/Paraíba do Sul: o caso da sub-bacia do Paraíbuna. Revista Brasileira de Geomorfologia, v. 20 n. 1, 119-136, 2019. https://doi.org/10.20502/rbg.v20i1.1498

PINTO C. P.; SILVA M. A. Mapa Geológico do Estado de Minas Gerais. Codemig/CPRM, 2014.

RAMOS, R. R. C.; MELLO, C. L.; SANSON, M. S. R. Bacias sedimentares brasileiras: Bacia de Resende. Phoenix, v. 7, n. 76, p. 1-6, 2005.

REZENDE, E. A.; SALGADO, A. A. R.; SILVA, J. R.; BOURLÈS, D.; BRAUCHER, R.; LÉANNI, L. Fatores Controladores da Evolução do Relevo no Flanco NNW do Rift Continental do Sudeste do Brasil: Uma Análise Baseada na Mensuração dos Processos Denudacionais de Longo-termo. Revista Brasileira de Geomorfologia, v. 14, n. 2, 2013. https://doi.org/10.20502/rbg.v14i2.416

RICCOMINI, C; SANT'ANNA, L. G.; FERRARI, A. L. Evolução geológica do Rift Continental do Sudeste do Brasil. In: MANTESSO-NETO, V.; BARTORELLI, A.; CARNEIRO, C. D. R.; BRITO-NEVES, B. B. (Ed.). Geologia do continente Sul-Americano: evolução da obra de Fernando Flávio Marques de Almeida. São Paulo: Beca, 2004. p. 383-405.

SAADI, A. Ensaio Sobre a Morfotectônica de Minas Gerais - tensões intra-placa, descontinuidades crustais e morfogênese. 1991. 285 f. Tese (Prof. Titular) - Instituto de Geociências, Universidade Federal de Minas Gerais, Belo Horizonte, 1991.

SAlgado, A. A. R.; SOBRINHO, L. C.; CHEREM, L. F.; VARAJÃO, C .A. C.; VARAJÃO, C. A. C.; BOULÈS, D. L.; BRAUCHER, R.; MARENT, B. R. Estudo da evolução da escarpa entre as bacias do Doce/Paraná em Minas Gerais através da quantificação das taxas de desnudação. Revista Brasileira de Geomorfologia, v. 13, n. 2, p. 213-222, 2012. https://doi.org/10.20502/rbg.v13i2.280 
SALGADO, A. A. R.; REZENDE, E. A.; BOURLÈS, D.; BRAUCHER, R.; SILVA, J. R.; GARCIA, R. A. Relief evolution of the Continental Rift of Southeast Brazil revealed by in situ-produced ${ }^{10} \mathrm{Be}$ concentrations in river-borne sediments. Journal of South American Earth Sciences, v. 67, p. 89-99, 2016. https://doi.org/10.1016/j.jsames.2016.02.002

SALVADOR, E. D.; RICCOMINI, C. Neotectônica da região do alto estrutural de Queluz (SP-RJ, Brasil). Revista Brasileira de Geociências, v. 25, n. 3, p. 151-164, 1995.

SANTOS, M. Serra da Mantiqueira e Planalto do Alto Rio Grande: a bacia terciária de Aiuruoca e evolução morfotectônica. 1999. 134 f. Tese (Doutorado em Geociências) - Instituto de Geociências e Ciências Exatas, Universidade Estadual Paulista, Rio Claro, 1999.

SARTI, T. P. Condicionantes litológicos e estruturais na evolução da rede de drenagem, Sapucaia-RJ, médio vale do Rio Paraíba do Sul. 2008. Dissertação (Mestrado em Análise de Bacias e Faixas Móveis) Faculdade de Geologia, Universidade do Estado do Rio de Janeiro, Rio de Janeiro, 2008.

SOUZA, D. H.; STUART, F. M.; RODÉS, A.; PUPIM, F. N.; HACKSPACHER, P. C. Controls on the erosion of the continental margin of southeast Brazil from cosmogenic ${ }^{10} \mathrm{Be}$ in river sediments. Geomorphology, v. 330, p. 163-176, 2019. https://doi.org/10.1016/j.geomorph.2019.01.020

SUMMERFIELD, M. A. Global Geomorphology: An introduction of the study of landforms. New York: Longman Scientific \& Technical, 1991. 537 p.

TADONO, T.; NAGAI, H.; ISHIDA, H.; ODA, F.; NAITO, S.; MINAKAWA, K.; IWAMOTO, H. Generation of the $30 \mathrm{~m}$-mesh global digital surface model by ALOS PRISM. The International Archives of the Photogrammetry, Remote Sensing and Spatial Information Sciences, Vol. XLI-B4, p.157-162, 2016. https://doi.org/10.5194/isprsarchives-XLI-B4-157-2016

TINÓS, T. M.; RIEDEL, P. S.; ZAINE, J. E. Técnicas de visualização de modelos digitais de elevação para o reconhecimento de elementos de análise do relevo. Geociências, v. 33, n. 2, p. 952-967, 2014.

TROUW, R. A. J.; RIBEIRO, A.; PACIUllO, F. V. P. Geologia da Folha Pouso Alto. In: PEDROSA SOARES, A. C.; NOCE, C. M.; TROUW, R. A. J.; HEILBRON, M. (Org.). Geologia e Recursos Minerais do Sudeste Mineiro, Projeto Sul de Minas- Etapa I. Belo Horizonte: COMIG - Companhia Mineradora de Minas Gerais, 2003.

TROUW, R. A. J.; PETERNEL, R.; RIBEIRO, A.; HEILBRON, M.; VINAGRE, R.; DUFFLES, P.; TROUW, C. C.; FONTAINHA, M.; KUSSAMA, H. H. A new interpretation for the interference zone between the southern Brasília belt and the central Ribeira belt, SE Brazil. Journal of South American Earth Sciences, v. 48, p. 43-57, 2013. https://doi.org/10.1016/j.jsames.2013.07.012

ZALÁN, P. V.; OLIVEIRA, J. B. A. Origem e evolução estrutural do Sistema de Riftes Cenozóicos do Sudeste do Brasil. Boletim de Geociências da Petrobrás. Rio de Janeiro, v. 13, n. 2, p. 269-300, 2005.

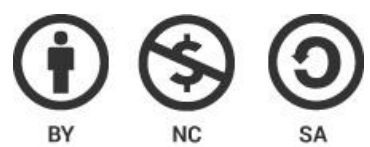

Este artigo é distribuído nos termos e condições do Creative Commons Attributions/AtribuiçãoNãoComercial-CompartilhaIgual (CC BY-NC-SA). 